\title{
Effects of a Participatory Ergonomics Intervention With Wearable Technical Measurements of Physical Workload in the Construction Industry: Cluster Randomized Controlled Trial
}

Mikkel Brandt ${ }^{1,2}, \mathrm{PhD}$; Pascal Madeleine ${ }^{2}$, DSc, PhD; Afshin Samani ${ }^{2}, \mathrm{PhD}$; Jeppe ZN Ajslev ${ }^{1}$, PhD; Markus D Jakobsen $^{1}$, PhD; Emil Sundstrup ${ }^{1}$, PhD; Lars L Andersen ${ }^{1,2}$, PhD

${ }^{1}$ National Research Centre for the Working Environment, Copenhagen, Denmark
${ }^{2}$ Sport Sciences, Department of Health Science and Technology, Aalborg University, Aalborg, Denmark

Corresponding Author:

Mikkel Brandt, $\mathrm{PhD}$

National Research Centre for the Working Environment

Lersø Parkalle 105

Copenhagen, DK-2100

Denmark

Phone: 4539165342

Email: $\underline{\text { mbp@nrcwe.dk }}$

\begin{abstract}
Background: Construction work frequently involves heavy physical work, and a reduction of the physical workload should have high priority. Technological development has made it possible to obtain field measurements with surface electromyography (sEMG), kinematics measured with inertial measurement units (IMUs), and video recordings. However, no studies have used these methods simultaneously to detect situations with excessive physical workload (events) during a working day. Thus, knowledge about these specific events may combat work-related risk factors. Participatory ergonomics (PE) has shown promising results, but whether it can be used as a tool to reduce the physical workload during construction work remains unknown.

Objective: This cluster randomized controlled trial investigated whether a PE intervention with technical measurements consisting of IMUs, sEMG, heart rate monitoring, and video recordings of physical workload could reduce the number of events with excessive physical workload during a working day. Furthermore, other outcomes were obtained from questionnaires.

Methods: A total of 80 male full-time construction workers (aged 19 to 67 years) were randomized at the cluster level (gang) to a PE intervention consisting of 3 workshops ( 7 gangs and 32 workers) or to a control group ( 8 gangs and 48 workers). The physical workload was recorded by technical measurements, that is, IMUs, sEMG, heart rate monitoring, and video recordings during a full working day at baseline and 3 and 6 months' follow-up. On the basis of the technical measurements, a custom-made computer program detected the situations (events) where the construction workers were exposed to excessive physical workload and used in the intervention. Differences in the number of events from baseline to follow-up between intervention and control were evaluated using linear mixed models (intention-to-treat), with individual nested in cluster as a random factor. Furthermore, questionnaires were filled out on test days.
\end{abstract}

Results: The results of the primary outcome showed no change in the number of events with excessive physical workload. However, compared with the control group, the other outcomes showed decreased general fatigue after a typical working day $(P=.001)$ and increased influence on own work $(P=.04)$.

Conclusions: This PE intervention with technical measurements did not reduce the number of events with excessive physical workload during construction work. However, the intervention led to decreased general fatigue and increased influence on own work.

Trial Registration: ClinicalTrials.gov NCT02498197; https://clinicaltrials.gov/ct2/show/NCT02498197 (Archived by WebCite at http://www.webcitation.org/74SZ3DIWS)

(J Med Internet Res 2018;20(12):e10272) doi: 10.2196/10272 


\section{KEYWORDS}

back pain; low back pain; shoulder pain; musculoskeletal pain; musculoskeletal diseases; occupational health; building industry; heavy industries; organizational ergonomics; action research

\section{Introduction}

\section{Background}

Work-related musculoskeletal disorders (WMSDs) such as low back pain and shoulder pain constitute a substantial problem for individuals, workplaces, and societies [1-3]. At the individual level, WMSDs increase risk of poor health, sick leave, and premature exit from the labor market $[1,4,5]$. For workplaces, workers with WMSDs have lower workability and are more likely to have long-term sickness absence [6,7]. For the societies, WMSDs lead to substantial expenses regarding treatment, lost production, and sickness absence [1,8]. Heavy physical work is a known risk factor for developing WMSDs [9,10]. In particular, heavy lifting, pushing or pulling, and working in awkward postures have been associated with low back pain [11] and sickness absence $[4,12,13]$. Construction work consists of a high degree of heavy physical work [14,15]. Consequently, a reduction of the physical workload to promote sustainable working careers [16] in construction work should have high priority. Moreover, a systematic review highlighted an urgent need for interventions focusing on reducing WMSDs in construction workers [17]. In addition, most field studies in the construction industry are based on self-reported measurements [17]. Hence, a more technical approach may enable objective evaluation of the loading and provide better grounds for targeted and effective interventions.

\section{Technical Measurements}

Technological development has made it possible to obtain field measurements with surface electromyography (sEMG) $[18,19]$, kinematics measured with inertial measurement units (IMU) [20-23], or a combination [24]. However, no studies have used sEMG, IMU, and video recordings obtained simultaneously to detect events with excessive physical workload (events) during a working day. Thus, knowledge about these specific events may be an important tool for engaging workers to combat work-related risk factors.

\section{Participatory Ergonomics}

In participatory ergonomics (PE), the workers are involved in the decision processes. Systematic reviews have reported that PE has positive effects on musculoskeletal symptoms [25] and thereby may lead to increased productivity and reduced occupational risk factors [26]. Furthermore, a systematic review has shown that participatory responsibility concerning the identification of risk factors, development of solutions, and implementation is important to succeed in the participatory process [27]. Nevertheless, the evidence for preventing neck-shoulder and low back pain through ergonomics interventions is questionable because the number of randomized controlled trials are limited [28].

\section{Objectives}

This cluster randomized controlled trial investigated whether a PE intervention with technical measurements could reduce the number of events with excessive physical workload during a working day in the construction industry We hypothesized that the PE intervention involving both managers and workers would lead to a reduction in the number of events of excessive physical workload.

\section{Methods}

\section{Study Design}

This study was a 2-armed, parallel group, single-blinded, cluster randomized controlled trial with allocation concealment performed at construction sites across Denmark from May 2016 to June 2017. Clusters were defined as construction gangs. The organization of construction work, that is, working in construction gangs, was the reason for choosing a cluster design. The intervention consisted of 3 workshops based on individual technical measurements of excessive physical workload. The technical measurements to detect excessive physical workload have previously been validated in controlled laboratory settings [29] and were conducted at baseline and 3 and 6 months' follow-up.

\section{Ethics}

According to the Helsinki declaration, participants received written and oral information about the purpose and content of the study before signing the informed consent form. The study was approved by the local ethical committee of Frederiksberg and Copenhagen (H-3-2010-062) and registered with the Danish Data Protection Agency (215-57-0074) and ClinicalTrials.gov (NCT02498197). The reporting followed the CONSORT statements for cluster randomized trials [30] and CONSORT eHealth [31] (Multimedia Appendix 1). Design of the effect evaluation and process evaluation have previously been reported $[32,33]$. This study reports data solely from the effect evaluation.

\section{Participants}

The inclusion criterion was full-time construction work. The exclusion criteria were life-threatening diseases and hypertension $>160 / 100 \mathrm{mmHg}$. A total of 9 participants were excluded before the baseline test. Moreover, 80 participants (15 clusters (gangs)) met the inclusion criteria and completed the baseline test. The flow of participant enrollment is illustrated in Figure 1.

\section{Randomization and Blinding}

The randomization was performed by a researcher who was not involved in data collection (LLA). Block randomization of the construction gangs was chosen for practical reasons and was performed continuously as the baseline tests were completed. The researchers performing the data collection were not aware of the block size or group allocation. Blinding of participants is not possible in behavioral interventions. The data analyst and the statisticians were blinded to group allocation. 
Figure 1. Participant's recruitment flowchart. TrpR: trapezius right; TrpL: trapezius left; ESR: erector spinae right; ESL: erector spinae left; IMU SH: inertial measurement unit, shank.

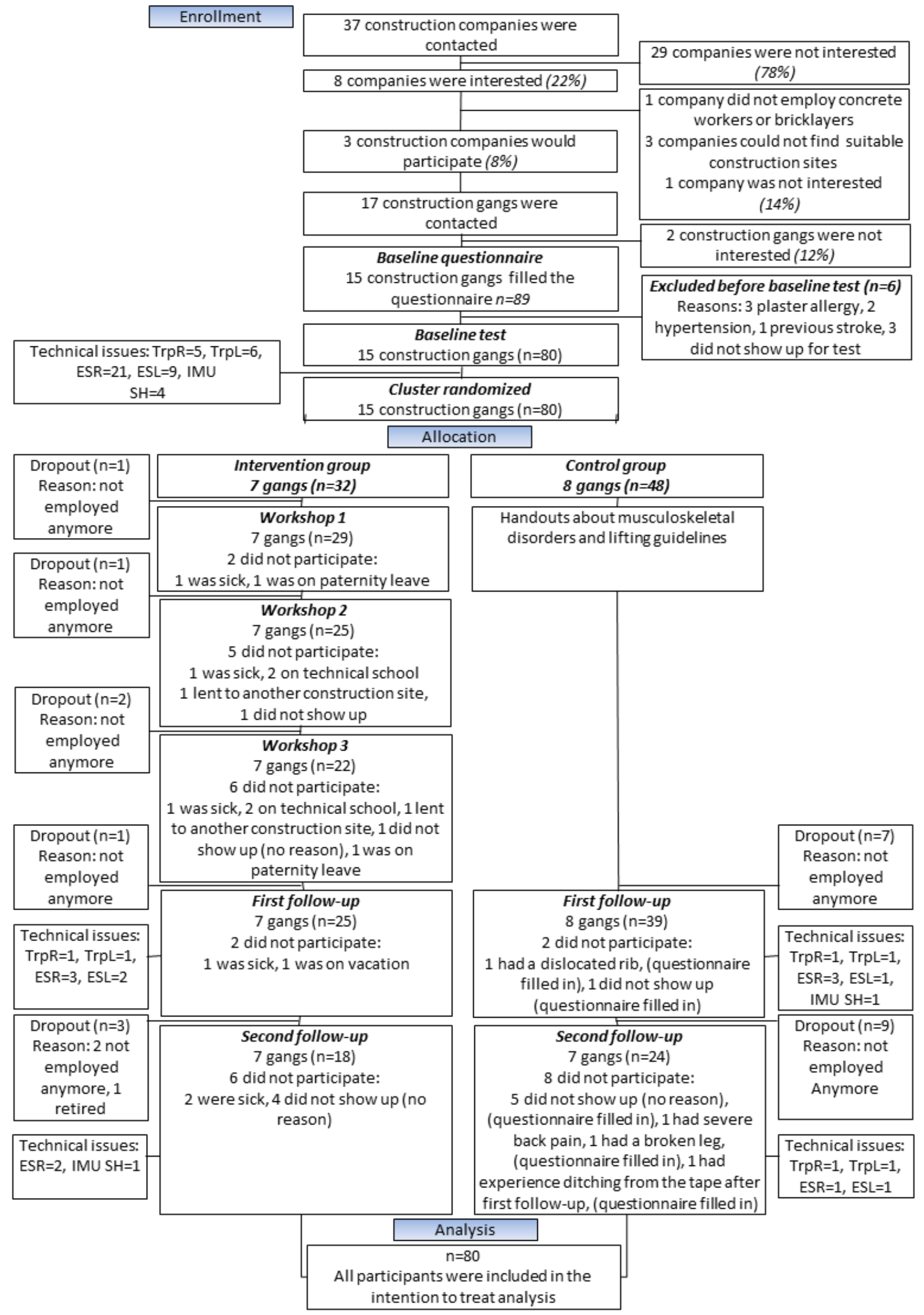




\section{Intervention}

The intervention was carried out at gang level and consisted of workshops or reading handouts for the intervention group and control group, respectively.

\section{Intervention Group}

The workshops were organized in a 3-phase structure inspired by an action research approach [34]. The programs aimed to create possibilities for change by enabling engagement between the technical measurements and the participants. The first workshop was designed with main inspiration from the future workshop; a type of workshop that usually consists of 3 phases: (1) critique, (2) utopia, and (3) realization [35]. In our design, the critique phase was replaced by an introduction of the video recordings of the participants' own work and a description of the physical workload measured in relation to each video recording. Subsequently, the participants decided which work situations should be modified during the intervention. In the utopian phase, the participants discussed in groups each selected work situation. The participants were to discuss and describe how the selected work process could be carried out in the best of all worlds with minimal physical exertion. In this phase, the participants were instructed not to take any barriers into account to facilitate creative resourcefulness. In the realization phase, the participants were asked to consider possibilities and barriers to reach the utopias. Furthermore, a plan of action was written.

In the second workshop, the participants were asked to recapture the focal points of the first workshop and to describe the progress concerning each of the selected topics in the first workshop. Then, they were encouraged to describe the barriers they had encountered in the process of reaching the goals of changing the working situations. Following this, the researchers described the current knowledge on organizational and social practices about WMSDs in the construction industry. The purpose of this was to nudge the participants to increased creativity and to challenge potentially frozen conceptions of how work should be done. Finally, the participants were encouraged to come up with further ideas on how to work toward the utopias or to aim for new utopias if they had reached their initial goals.

The third workshop had the purpose of anchoring initiatives. The researchers initially asked the participants to describe the status of the goals set earlier in the project. Then, the participants were invited to discuss whether the organization would be able to implement the initiatives of the project into long-term working practice and to come up with ideas for initiatives that could help secure this long-term anchorage.

\section{Control Group}

The control group received handouts about WMSDs [36] and lifting guidelines from The Danish Working Environment Authority [37]. These handouts described the association between WMSDs and the impact on working life, regulations for the prevention of WMSDs, and which precautions should be taken to limit WMDSs [36]. Furthermore, the handouts described the regulations for lifting, pushing and pulling, and the risk of injuries [37].

\section{Technical Measurements}

At baseline and 3 and 6 months' follow-up, the participants were equipped with sEMG, IMU, cameras, and heart rate monitors. The sEMG, IMU, and camera were synchronized [29], whereas the heart rate monitor was used to estimate the overall activity level during the working day.

The procedure for placement of sEMG electrodes is described elsewhere $[29,32,38]$. In short, sEMG electrodes (Blue Sensor $\mathrm{N}-00-\mathrm{S} / 25$, Ambu A/S, Ballerup, Denmark) were placed bilaterally over the erector spinae and the upper trapezius muscles [39] according to the Surface Electromyography for the Non-Invasive Assessment of Muscles (SENIAM) recommendations [40]. A reference electrode was placed over the C7 vertebra. The sEMG signals were amplified 19.5 times using a 24-bit portable data-logger (Nexus10, Mind Media, Herten, Netherlands) and sampled at $1024 \mathrm{~Hz}$.

IMU including triaxial accelerometer and gyroscopes (ActiGraph GT9X Link, ActiGraph, Pensacola, United States) were positioned on the upper back at T1-T2 level [41] and the thigh. The latter was used for obtaining the number of steps per day [42]. When positioned, the IMUs were calibrated in a standing neutral position (N-pose) for 15 seconds. Kinematics data were sampled at $100 \mathrm{~Hz}$.

A body-worn video camera with a resolution of $848 \times 480 / 30 F$ (Reveal Media, RS2-X2L, Hampton Wick, Surrey, United Kingdom) was placed around the chest and recorded the area in front of the participant.

For heart rate monitoring electrodes ( $\varnothing$ : $68 \mathrm{~mm}$; Blue Sensor VL-00-S/25, Ambu A/S, Ballerup, Denmark) were positioned just below the apex of the sternum and laterally under the left pectoralis major muscle $[43,44]$, before connecting to the heart rate monitor (Actiheart, CamNtech Ltd, Cambridge, United Kingdom). Heart rate was sampled at $128 \mathrm{~Hz}$ and interpolated with a resolution of $+/-1 \mathrm{~ms}$.

The data from the IMU, sEMG, and cameras were synchronized using a custom-made device and a MatLab (2013a) program. A $2 \mathrm{mV}$ trigger signal was sent to the EMG logger. At the same time, the IMUs were turned 95 degrees using a rotary solenoid (GDAX 050 X20 B71 24V, 100\% ED). The synchronization with the cameras was obtained by having the cameras record a custom-made flashing device that flashed at the same time as the signal was sent to the sEMG logger box and the rotary solenoid. The synchronization was made before the equipment was positioned on the participant and repeated after the working day [29].

\section{Test Protocol}

The test protocol consisted of (1) maximal voluntary contractions (MVCs) for the lower back and shoulders, (2) reference lifting, and (3) calibration of the IMUs.

The MVCs for the upper trapezius was performed with a strap around the wrist in a standing position with 90-degree bilateral shoulder abduction. The participants performed maximal bilateral shoulder abduction. For the MVCs for the erector spinae, the participants were fixed with a strap around the shoulders with a slight flexion in their back leaning toward a 
pillow at the height of the anterior iliac spine on the hip. The participants performed 3 repetitions for each MVC with a 30 seconds rest period between the trials. The participants ramped up the force to maximum in 2 to 3 seconds and held it for 3 seconds. The participants performed 10 reference lifts from floor to table (73 cm high) with a $20 \mathrm{~kg}$ box (width: $56 \mathrm{~cm}$, length: $34 \mathrm{~cm}$, and height: $20 \mathrm{~cm}$ ) using a forearm horizontal distance. From a starting standing position, the participants descended without load and lifted the box from the floor onto the table. After a pause of 2 seconds, they lifted the box to the floor and returned to starting position. Following a break of 2 seconds, the lifting cycle was repeated. The IMUs were calibrated by having the participants standing in a neutral position (N-pose) for 15 seconds. After these preliminary steps, the participants started their planned work and the attached equipment continuously captured data.

\section{Data Analysis-Event Detection}

The analyses for detecting the events are described in detail elsewhere [29]. In short, the sEMG segments corresponding to the references lifts and the MVC trials were extracted. For each of the MVC trials, the sEMG root mean square (RMS) was calculated over $500 \mathrm{~ms}$ epochs with $20 \%$ overlap between successive epochs. Then the maximum of calculated RMS across the epochs was found, and out of the $3 \mathrm{MVC}$ trials, the highest RMS value was considered as the maximum voluntary electrical activity. Similarly, the 90th percentile of calculated RMS during the reference lift was considered as the reference threshold. Subsequently, the recorded signals during the working time were analyzed over 10-second nonoverlapping epochs. Similar to what is described above, in each epoch, the 90th percentile of the calculated EMG RMS was derived, and the extent of forward and sideways inclination of the IMU concerning the $\mathrm{N}$-pose position was calculated [45]. During the working time, each of the 10-second epochs were labeled an event if the calculated sEMG amplitude was higher than the event threshold (either the average of the reference lifts in the morning and afternoon or $50 \%$ of the average MVC [46] in the morning and afternoon) for at least two of the muscles. Furthermore, for the erector spinae muscle on both sides, the event threshold was linearly decayed based on the calculated forward and sideways inclination such that the threshold would be reduced to its half at 90 degrees forward or 30 degrees sideways inclinations and it would be fixed beyond that level of inclination. The minimum of the modified threshold for the forward and sideways inclination was utilized as the modified threshold. If any of the calculated sEMG RMS over the 10-second epochs for the erector spinae on both sides was greater than the modified threshold, the 10-second epoch was labeled as an event as well. Furthermore, as exploratory analyses, the number of events was calculated based on a higher reference value of $150 \%$ of the sEMG from the reference lifts and 50\% of the sEMG from MVCs. The criteria for events from the analyses were that at least two muscles should exceed the limit.

\section{Outcomes}

\section{Primary Outcome}

The primary outcome was defined as the change in the number of events with excessive physical workload from baseline to follow-up. The reference lift of $20 \mathrm{~kg}$ used for normalization purposes was a deviation from the protocol study [32] as we planned to use $30 \mathrm{~kg}$. However, because $30 \mathrm{~kg}$ exceeds the acceptable lifting limit of The Danish Working Environment Authority, we chose to decrease the load.

\section{Other Outcomes}

Other outcomes were obtained from previously established and validated questionnaires and included physical (Borg category ratio 10 scale [Borg CR10]) [47,48], psychosocial, and organizational conditions (AH2012 and COPSOQ) [49-51]. Furthermore, the pain intensity in the last week (WAS-scale) [32] was enquired.

\section{Sample Size}

The sample size was calculated based on the observed changes in the level of muscular activity during a working day in different occupational groups with pronounced lifting [19]. The power calculation showed that 17 participants in each group were needed to demonstrate a reduction of $20 \%$ in normalized sEMG assuming an SD of approximately $20 \%$ in normalized sEMG between individuals and a type 1 risk of $5 \%$ and power of $80 \%$. Due to the cluster design and including an inflation factor of 1.5, 26 participants were required in each group [32]. For generalizability and risk of dropouts, we aimed to recruit 10 construction gangs of 3 to 5 individuals in each group, that is, a total of 80 participants.

\section{Statistics}

$t$ tests assessed possible group differences at baseline. The difference from baseline to follow-up between the intervention and control groups was evaluated using a linear mixed model. The number of events was log-transformed because the residuals were not normally distributed. Factors included in the model were group (intervention and control), time (baseline, first follow-up, and second follow-up), and group-by-time interaction. The analysis was adjusted for the baseline value of the outcome, age, gender, duration of measuring time, mean heart rate, number of steps, and muscle strength. Individual nested in cluster was included as a random factor. Analyses were performed using SAS statistical software (Proc Mixed, SAS version 9.4) according to the intention-to-treat principle, including all participants $(n=80)$ regardless of loss to follow-up. The estimation method was restricted maximum likelihood with degrees of freedom based on the Kenward-Roger approximation. $P$ levels $\leq .05$ were accepted as statistically significant. Outcomes are reported as within- and between-group least square mean differences with 95\% CIs. Furthermore, Fischer exact test was used to test for differences in questions with categorical response variables.

\section{Results}

\section{Participant Characteristics}

Table 1 shows the baseline characteristics of the participants. Age was higher in the control group compared with the intervention group $(P=.02)$, which was controlled for in the statistics by including age as a covariate. At the first follow-up test, 12 participants dropped out, and 4 participants did not show 
up for the test. At the second follow-up test, 12 participants dropped out, and 14 participants did not show up for the test. Hence, 42 participants completed the study (Figure 1). All dropouts were included in analyses.

\section{Primary Outcome}

The results showed no group-by-time interaction effect $(P=.75)$ and $(P=.51)$ for the number of events obtained using technical equipment in the unadjusted and adjusted analysis, respectively (Table 2). The results show a within-group difference (time effect) in the number of events from baseline to the first follow-up test (unadjusted, $P=.002$ and adjusted $P=.05$ and (unadjusted $P<.001$ and adjusted $P<.001$ ) for the intervention and control group, respectively. Furthermore, a within-group difference was observed from baseline to second follow-up in the unadjusted analysis for the intervention and control group $(P<.01$ and $P<.001)$, respectively. The exploratory analyses confirmed the results of the primary outcome, that is, no significant group-by-time interaction (Table 2).

The analyses of heart rate and step count showed no group-by-time interaction or within-group difference. However a between-group difference was observed at baseline, first and second follow-up, and at baseline for heart rate $(P<.001, P=.049$, and $P=.003$, respectively). This between-group difference was also observed for the step count at baseline $(P=.004)$ but not at the follow-ups. The mean heart rate was 100 (95\% CI 96 to 104), 101 (95\% CI 97 to 105), and 100 (95\% CI 96 to 105) and 91 (95\% CI 88 to 95), 95 (95\% CI 92 to 99), and 91 (95\% CI 87 to 95$) \mathrm{bpm}$ for the intervention and control group at baseline, first follow-up, and second follow-up, respectively. The mean number of steps adjusted for length of the working day were 5952 (95\% CI 5517 to 6387), 5479 (95\% CI 5023 to 5934), and 5980 (95\% CI 5372 to 6588 ) and 5133 (95\% CI 4791 to 5475), 5340 (95\% CI 4958 to 5722 ), and 5320 (95\% CI 4852 to 5788) steps per day for the intervention and control group at baseline, first follow-up, and second follow-up, respectively.

\section{Other Outcomes}

The results from the other outcomes are presented in Tables 3 and 4. In the intervention group, the results showed a within-group decrease in general fatigue after a typical working day $(P=.001$; Table 3$)$ from baseline to second follow-up and in influence on own work from baseline to first follow-up $(P=.04$; Table 3$)$. The remainder of the other outcomes showed no effect from the intervention (Tables 3 and 4).

\section{Adverse Events}

No adverse events were reported. 
Table 1. Basic characteristics of the participants in the study.

\begin{tabular}{|c|c|c|}
\hline Characteristics & Intervention group & Control group \\
\hline Number of participants, $\mathrm{n}$ (all males) & 32 & 48 \\
\hline Age in years, mean $(\mathrm{SD})$ & $34.2^{\mathrm{a}}(12.5)$ & $41.2^{\mathrm{a}}(12.5)$ \\
\hline Height in centimeters, mean (SD) & $180.0(6.2)$ & $180.1(7.2)$ \\
\hline Weight in kilograms, mean (SD) & $85.0(12.2)$ & $86.4(14.6)$ \\
\hline Weekly working hours, mean (SD) & $39.1(4.8)$ & $38.1(2.5)$ \\
\hline Gang size, mean (SD) & $4.5(1.5)$ & $6.0(2.3)$ \\
\hline \multicolumn{3}{|l|}{ Smokers, n (\%) } \\
\hline Yes & $15(47)$ & $17(36)$ \\
\hline No & $17(53)$ & $31(64)$ \\
\hline \multicolumn{3}{|l|}{ Current position, $\mathbf{n}(\%)$} \\
\hline Concrete workers & $25(78)$ & $27(56)$ \\
\hline Bricklayers & $5(16)$ & $19(40)$ \\
\hline Others (eg, bricklayer's assistant) & $2(6)$ & $2(4)$ \\
\hline \multicolumn{3}{|l|}{ Term of employment, $\mathbf{n}(\%)$} \\
\hline Hourly paid & $13(41)$ & $35(73)$ \\
\hline Monthly paid & $1(3)$ & $0(0)$ \\
\hline Paid according to performance & $18(56)$ & $13(27)$ \\
\hline \multicolumn{3}{|l|}{ Experience in construction, $\mathrm{n}(\%)$} \\
\hline$<3$ years & $4(12)$ & $4(8)$ \\
\hline 4-10 years & $14(44)$ & $13(27)$ \\
\hline$>11$ years & $14(44)$ & $31(65)$ \\
\hline \multicolumn{3}{|c|}{ How often can you take it easy and still reach your working tasks?, n (\%) } \\
\hline Always & $0(0)$ & $1(2)$ \\
\hline Often & $6(19)$ & $11(23)$ \\
\hline Sometimes & $16(50)$ & $23(48)$ \\
\hline Rarely & $9(28)$ & $12(25)$ \\
\hline Never & $1(3)$ & $1(2)$ \\
\hline \multicolumn{3}{|c|}{ How exhausting do you find your regular work? $\left(\operatorname{Borg} \mathrm{CR}_{10}{ }^{\mathrm{b}}\right), \mathbf{n}(\%)$} \\
\hline Light $(0-2.5)$ & $1(3)$ & $6(12.5)$ \\
\hline Moderate (3-5) & $16(50)$ & $36(75)$ \\
\hline Hard (6-10) & $15(47)$ & $6(12.5)$ \\
\hline \multicolumn{3}{|c|}{ How often do you feel pain in your body? $n(\%)$} \\
\hline Every day & $10(31)$ & $16(33)$ \\
\hline A few times a week & $10(31)$ & $8(17)$ \\
\hline A few times a month & $8(25)$ & $18(38)$ \\
\hline Maximum a few times a year & $4(13)$ & $6(12)$ \\
\hline Never & $0(0)$ & $0(0)$ \\
\hline \multicolumn{3}{|c|}{ Degree of difficulty in the low back within the last week $\left(0-10 \mathrm{VAS}^{\mathrm{c}}\right), \mathrm{n}(\%)$} \\
\hline $0-3$ & $13(42)$ & $24(52)$ \\
\hline $4-6$ & $10(32)$ & $15(33)$ \\
\hline $7-10$ & $8(26)$ & $7(15)$ \\
\hline
\end{tabular}




\begin{tabular}{lll}
\hline Characteristics & Intervention group & Control group \\
\hline Degree of difficulty in the upper back within the last week $\left(\mathbf{0 - 1 0} \mathbf{~ V A S}^{\mathbf{c}}\right), \mathbf{n}(\boldsymbol{\%})$ & $19(61)$ & $35(76)$ \\
$0-3$ & $8(26)$ & $9(20)$ \\
$4-6$ & $4(13)$ & $2(4)$ \\
$7-10$ & $23(74)$ & $32(70)$ \\
Degree of difficulty in the shoulders within the last week $\left.\mathbf{( 0 - 1 0 ~} \mathbf{~ V A S}^{\mathbf{c}}\right), \mathbf{n}(\boldsymbol{\%})$ & $6(19)$ & $11(24)$ \\
$0-3$ & $2(6)$ & $3(6)$ \\
$4-6$ & & 2 \\
\hline
\end{tabular}

${ }^{\mathrm{a}}$ Difference between groups at baseline, $P=.02$.

${ }^{\mathrm{b}}$ Borg CR10: Borg category ratio 10 scale.

${ }^{\mathrm{c}}$ VAS: visual analog scale.

Table 2. Results of the primary outcome (change from baseline to follow-up in events with excessive physical workload during a working day) from the mixed-model analysis.

\begin{tabular}{|c|c|c|c|c|c|c|c|}
\hline Group & & Within-group difference & & & Between-group difference a & follow-up & \\
\hline Group & Baseline & $\begin{array}{l}\text { First follow- } \\
\text { up }\end{array}$ & $\begin{array}{l}\text { Second fol- } \\
\text { low-up }\end{array}$ & $P$ value & First follow-up & $\begin{array}{l}\text { Second follow- } \\
\text { up }\end{array}$ & $P$ value \\
\hline
\end{tabular}

\section{Primary outcome}

$100 \%$ sEMG $^{\mathrm{a}}$ from reference lifts-unadjusted $(95 \% \mathrm{CI})$

\begin{tabular}{|c|c|c|c|c|c|c|c|c|c|}
\hline Intervention & $5.2(5$ to 5.5$)$ & $5.8(5.5$ to 6.1$)$ & .002 & $5.8(5.4$ to 6.1$)$ & .01 & $-0.1(-0.4$ to 0.3$)$ & .72 & $0(-0.4$ to 0.4$)$ & .94 \\
\hline Control & $5.1(4.9$ to 5.3$)$ & $5.9(5.6$ to 6.1$)$ & $<.001$ & $5.8(5.5$ to 6$)$ & $<.001$ & $-^{b}$ & - & - & - \\
\hline \multicolumn{10}{|c|}{ 0\% sEMG from reference lifts-adjusted (95\% CI) } \\
\hline Intervention & $5.4(5.1$ to 5.7$)$ & $5.8(5.5$ to 6.1$)$ & .05 & $5.7(5.3$ to 6.0$)$ & .3 & $0(-0.4$ to 0.4$)$ & .89 & $0.1(-0.4$ to 0.6$)$ & .62 \\
\hline Control & $5.1(4.9$ to 5.4$)$ & $5.8(5.6$ to 6.1$)$ & $<.001$ & $5.5(5.2$ to 5.9$)$ & .052 & - & - & - & \\
\hline
\end{tabular}

Explorative analysis

$150 \%$ sEMG from reference lifts $(95 \% \mathrm{CI})$

$\begin{array}{llllllllll}\text { Intervention } & 3.8(3.5 \text { to } 4.2) & 4.3(3.9 \text { to } 4.8) & .06 & 3.8(3.3 \text { to } 4.3) & .94 & 0.3(-0.2 \text { to } 0.8) & .21 & 0.4(-0.2 \text { to } 0.9) & .89 \\ \text { Control } & 3.6(3.2 \text { to } 3.9) & 4.0(3.6 \text { to } 4.4) & .08 & 3.9(3.4 \text { to } 4.3) & .3 & - & - & - & -\end{array}$

$50 \%$ sEMG from MVCs $^{\mathrm{c}}(\mathbf{9 5 \%} \mathrm{CI})$

\begin{tabular}{llllllllll} 
Intervention & $4.2(3.7$ to 4.8$)$ & $4.2(3.6$ to 4.9$)$ & .97 & $4.8(3.9$ to 5.6$)$ & .35 & $0.2(-0.6$ to 1.1$)$ & .6 & $0.6(-0.5$ to 1.7$)$ & .3 \\
Control & $4.0(3.5$ to 4.4$)$ & $4.0(3.4$ to 4.6$)$ & .89 & $4.2(3.4$ to 4.9$)$ & .62 & - & - & - & - \\
\hline
\end{tabular}

a sEMG: surface electromyography.

${ }^{\mathrm{b}}$ Not applicable.

${ }^{\mathrm{c}}$ MVCs: maximal voluntary contraction. 
Table 3. Results from the other outcome.

\begin{tabular}{|c|c|c|c|c|c|c|}
\hline \multirow[t]{2}{*}{ Group and scale } & \multirow[t]{2}{*}{ Baseline } & \multirow[t]{2}{*}{ First follow-up } & \multirow[t]{2}{*}{ Second follow-up } & \multicolumn{2}{|c|}{ Between-group difference at follow-up } & \multirow[t]{2}{*}{ Time effect, $P$ value } \\
\hline & & & & First follow-up & Second follow-up & \\
\hline \multicolumn{7}{|c|}{ Heaviest lift last week, $0-10$ scale $(95 \%$ CI $)$} \\
\hline Intervention & $6.7(6.1$ to 7.2$)$ & $6.8(6.2$ to 7.4$)$ & $6(5.3$ to 6.7$)$ & $0.2(0.6$ to 0.1$)$ & $-0.1(-1$ to 0.8$)$ & .52 \\
\hline Control & $6.2(5.7$ to 6.6$)$ & 6.5 (6 to 7$)$ & $6.1(5.5$ to 6.6$)$ & $-^{\mathrm{a}}$ & - & - \\
\hline \multicolumn{7}{|c|}{$\begin{array}{l}\text { General fatigue after a typical working day, 5-point scale (not tired, a little tired, tired, very tired, and exhausted) converted to } 0-100(95 \% \\
\text { CI) }\end{array}$} \\
\hline Intervention & $41.1(37.2$ to 45$)$ & 40.8 (36.6 to 45$)$ & $35.6(31$ to 40.3$)$ & $-6.1(-11.7$ to -0.5$)$ & $-11.2(-17.4$ to -5$)$ & .001 \\
\hline Control & $39.4(36.2$ to 42.5$)$ & $46.9(43.4$ to 50.4$)$ & $46.8(42.9$ to 50.7$)$ & - & - & - \\
\hline \multicolumn{7}{|c|}{ How physically strenuous do you usually perceive your current work?, Borg CR10 scale ${ }^{b}$ (95\% CI) } \\
\hline Intervention & $4.8(4.2$ to 5.3$)$ & $4.4(3.9$ to 5$)$ & $5(4.4$ to 5.7$)$ & $-0.4(-1.1$ to 0.4$)$ & $0.5(-0.3$ to 1.4$)$ & .10 \\
\hline Control & 4.3 (3.9 to 4.8$)$ & $4.8(4.3$ to 5.3$)$ & $4.5(3.9$ to 5$)$ & - & - & - \\
\hline \multicolumn{7}{|c|}{ How much influence do you have on your work, 5 -point scale (very much, much, some, little, very little) converted to 0-100 (95\% CI) } \\
\hline Intervention & $59.6(56.6$ to 62.5$)$ & $60.4(57.3$ to 63.6$)$ & $58.9(55.4$ to 62.5$)$ & $5.6(1.5$ to 9.8$)$ & $-0.1(-4.8$ to 4.6$)$ & .04 \\
\hline Control & $60.3(58$ to 62.7$)$ & $54.8(52.2$ to 57.4$)$ & $59(56$ to 62$)$ & - & - & - \\
\hline \multicolumn{7}{|c|}{ Do you wish more influence on your work, 2-point scale (yes or no) converted to 0-100 (95\% CI) } \\
\hline Intervention & $39.3(29.6$ to 49$)$ & 49.4 (39 to 59.7$)$ & 48.7 (37.3 to 60.2$)$ & $-3.9(-17.6$ to 9.7$)$ & $0.1(-15.3$ to 15.4$)$ & .85 \\
\hline Control & 44.1 (36.3 to 51.9$)$ & $53.3(44.7$ to 61.9$)$ & 48.7 (38.9 to 58.5$)$ & - & - & - \\
\hline
\end{tabular}

${ }^{\mathrm{a}}$ Not applicable.

${ }^{\mathrm{b}}$ Borg CR10: Borg category ratio 10 scale.

Table 4. Results from the other outcome. Numbers indicate the participants who answered the question (percent of the population who answered the question).

\begin{tabular}{|c|c|c|c|c|c|c|c|c|c|c|c|c|}
\hline \multirow{2}{*}{$\begin{array}{l}\text { Group and ques- } \\
\text { tion }\end{array}$} & \multicolumn{4}{|c|}{ Baseline } & \multicolumn{4}{|c|}{ First follow-up } & \multicolumn{4}{|c|}{ Second follow-up } \\
\hline & Daily & Weekly & $\begin{array}{l}\text { Hardly } \\
\text { ever }\end{array}$ & $P$ value $^{\mathrm{a}}$ & Daily & Weekly & $\begin{array}{l}\text { Hardly } \\
\text { ever }\end{array}$ & $P$ value $^{\mathrm{a}}$ & Daily & Weekly & $\begin{array}{l}\text { Hardly } \\
\text { ever }\end{array}$ & $P$ value $^{\mathrm{a}}$ \\
\hline \multicolumn{13}{|c|}{ How often do you perform heavy lifting?, n (\%) } \\
\hline Intervention & $21(66)$ & $11(34)$ & $0(0)$ & .2 & $14(50)$ & $13(46)$ & $1(4)$ & .54 & $11(50)$ & $11(50)$ & $0(0)$ & .22 \\
\hline Control & $23(48)$ & $24(50)$ & $1(2)$ & $-{ }^{b}$ & $19(48)$ & $16(40)$ & $5(12)$ & - & $10(32)$ & $18(58)$ & $3(10)$ & - \\
\hline \multicolumn{13}{|c|}{ How often do you feel pain in your body (eg, arms, hands, knees, shoulders, and back)?, n (\%) } \\
\hline Intervention & $10(31)$ & $10(31)$ & $12(38)$ & .32 & $8(29)$ & $7(25)$ & $13(46)$ & .53 & $3(14)$ & $10(45)$ & $9(41)$ & .59 \\
\hline Control & $16(33)$ & $8(17)$ & $24(50)$ & - & $14(34)$ & $13(33)$ & $13(33)$ & - & $8(26)$ & $12(39)$ & $11(35)$ & - \\
\hline \multicolumn{13}{|c|}{ Do you take analgesics because of pain in your neck/shoulders or back?, $\mathbf{n}(\%)$} \\
\hline Intervention & $1(3)$ & $1(3)$ & $30(94)$ & 65 & $1(4)$ & $2(7)$ & $25(89)$ & .86 & $0(0)$ & $1(5)$ & $21(95)$ & .37 \\
\hline Control & $3(6)$ & $4(8)$ & $41(86)$ & - & $2(5)$ & $5(13)$ & $33(82)$ & - & $2(6)$ & $4(13)$ & $25(81)$ & - \\
\hline
\end{tabular}

${ }^{\mathrm{a} B}$ Between group differences.

${ }^{\mathrm{b}}$ Not applicable.

\section{Discussion}

\section{Principal Findings}

This study is the first to detect events with excessive physical workload using only technical measurements, individual thresholds, and applying these measurements in a PE intervention. The results of this cluster randomized controlled trial showed that a PE intervention did not decrease the number of events during a working day. Other outcomes showed positive effects on influence on own work and general fatigue after a typical working day, but not on pain, perceived workload, and how often heavy lifting was performed. 


\section{Interpretation of Results}

Technical measurements have the advantage of being objective. Furthermore, it builds on from standardized analytical procedures of the raw data, rather than, for example, self-reports or visual observations $[52,53]$. We have recently shown that the intraday reliability for sEMG during lifting tasks is acceptable in laboratory conditions [38]. Furthermore, the method for detecting events of the lower back and shoulder based on sEMG and IMU from the upper back has shown high accuracy in a laboratory setting [29]. Thus, we are certain the measurement method per se was not cause of the nonsignificant findings.

There was no group-by-time interaction for the primary outcome, which was the change in the number of events from baseline to follow-up. However, the number of events increased over time in both groups, and because this technical detection was used for the first time in a field study, we performed exploratory analyses with the detection of events based on $150 \%$ of the sEMG obtained during the reference lifts and 50\% MVCs (Table 2 ). This confirmed that there was no effect of the intervention on the primary outcome. However, the exploratory analysis did not show a within-group difference as seen in the preplanned analysis [32]. This could be related to the threshold, which might have been too low, and we might have seen a more stable normalization factor by using, for example, $30 \mathrm{~kg}$ as reference value. However, the within-group increase in both groups could also be related to the organization of construction work, which is characterized by a distinctive variation regarding work pace, work tasks, and work processes. This variation makes it challenging to conduct intervention studies with field measurements in the construction industry as the inherent variance will necessitate a larger sample size than anticipated based on laboratory measurements. As the participants were further into the process of their current construction project during the follow-up than at baseline, this may have increased the work pace due to incentive reasons. However, analyses of heart rate and step count did not support this speculation. Another possibility could be that the participants were more aware of the measurements at baseline and therefore acting more carefully to avoid heavy lifting. This effect may have diminished during follow-up.

The other outcomes showed effects on influence at work and general fatigue after a typical working day. The difference in influence on own work was only seen at first follow-up and was primarily driven by the control group experiencing a decrease in influence. This may indicate that the control group felt neglected compared with the intervention group who attended the workshops and had the opportunity to bring forward new ideas. The second follow-up was 3 months after the last workshop. Therefore, the feeling of being neglected might have eased off, likely because the tangible consequences of the intervention were often only "increased attention to physically stressful work" as shown in Multimedia Appendix 2, rather than real changes in the working process or technical assistive devices. The decrease in general fatigue after a typical working day in the intervention group indicates that some effect occurred in response to the intervention despite not being effective in reducing events. It can be speculated that the implemented solutions led to work that reduced light loads, repetitive work, or made the work processes more efficient in general and thus less physically fatiguing. A review has shown reductions in physical work demands and musculoskeletal symptoms if mechanical lifting devices are introduced at workplaces [54], and other studies have shown a decreased discomfort [55] or ergonomic improvement when introducing devices for raised bricklaying that may decrease the physical workload during construction work [56]. As the majority of the implemented suggestions concerned technical assistive devices, it can be speculated that the increased use of assistive devices may partially explain the decrease in general fatigue.

The majority of the suggestions were related to assistive devices (Multimedia Appendix 2) and are in accordance with previous findings, where the workers identified ergonomic solutions using assistive devices to reduce WMSDs, but the support from the contractors to implement these was lacking [57]. Accordingly, other studies suggest that support from the management is critical for providing changes in the construction industry $[58,59]$. In this study, the management was often not willing to support the suggestions if they involved increased costs. Hence, more support from the management might have had a positive effect [60]. The intervention might have failed in involving the management as we underestimated the challenge of obtaining economical and persistent commitment from the management. However, this seems to be a highly common but underaddressed issue in participatory research [27,61].

There may be several contributing factors to the high physical demands of construction work, of which work organization plays an important role. Construction work in Denmark is characterized by being organized in small working units, often on a group-based wage, which can be associated with an increased risk factor for WMSDs [62] and can induce a group pressure within the gang to get the work done at a certain time without taking pain into consideration [63]. Studies suggest that both structural and cultural changes are necessary to create changes in the construction industry [57,64]. The lack of effect from the intervention in this study might be related to the culture in the construction industry where WMSDs are an accepted part of being a construction worker $[65,66]$.

\section{Perspectives}

With the rapid technological development, this method could be integrated into portable devices connected to, for example, mobile phones and thereby provide the worker with direct feedback to prevent work tasks with excessive physical workload.

\section{Strengths and Limitations}

A strength of this study is the cluster randomized design, making it possible to intervene at gang level, thus reducing the risk of a number of biases associated with nonrandomized studies. However, there are also known challenges of conducting behavioral randomized controlled trials, for example, blinding of participants or potential participants and supervisors who do not accept randomization [67]. Another strength is the use of technical measurements to quantify the workload rather than relying on self-reports or observations. 
A limitation of this study is that the number of dropouts was higher than expected, resulting in reduced statistical power. The terms of employment in the construction industry are dominated by short-term contracts, which resulted in a relatively high turnover of workers in the participating gangs in this study. This affected the number of participants employed over the entire intervention period. In research involving randomized controlled trial, it is preferable to have a stable group of participants. However, to our knowledge, no participants drop out of the study due to a lack of willingness to participate but were missing at random, and all participant were included in the intention-to-treat analysis. To fully control a randomized controlled trial in the construction industry showed to be extremely difficult due to, for example, variation in work tasks performed during a working day and sudden changes based on unpredictable incidents at the construction site. On the other hand, a considerable strength of this study is that the measurements have been conducted during actual construction work. Furthermore, it is a limitation that the size of the individual clusters was larger than anticipated, which also reduced the statistical power due to intracluster correlation. In general, the variance in measurements was also higher than expected. Due to these factors, future studies would need to recruit a much larger sample size to be randomized. On the other hand, the results of this study do not indicate that a relevant between-group difference would be reached even with a larger sample size.

The loss of data from sEMG, especially from the erector spinae muscles at baseline, was also a limitation. This loss of sEMG data was primarily caused by electrodes that slipped off, and future studies should minimize this loss of data by securing the sEMG cables such that excessive sweating of the participants does not compromise the skin-electrode impedance. Larger band aids over the electrodes or performing the measurements during the cooler season of the year when sweating is not a big issue might also help.
The inherent variation in daily working tasks at the construction sites is a practical challenge because the necessary sample size can easily grow to a level that is not realistic to achieve. We tried to control this by having close contact with the construction sites and conducting measures on the workers during similar working tasks, but this was not always possible. However, we compensated for this by controlling for steps and heart rate in the analysis.

During the recruitment, we were in contact with many small-scale construction companies that were unable to participate because their job tasks did not permit the long follow-up time in this study. Hence, we only included large-scale construction companies; thus, one should be cautious about generalization of our results to small-scale construction companies. On the other hand, changes are often even more difficult to implement in smaller companies where resources are scarce. It is, therefore, unlikely that inclusion of smaller companies would have changed the main conclusion of the study.

Finally, the difference in age and, partly, experience between the intervention and control group could be limitations to the study. Therefore, we controlled for age in the statistical analysis, but it cannot be ruled out that a more experienced intervention group could have increased the implementation rate of the suggested solution and thus reduced the number of events with excessive physical workload following the intervention.

\section{Conclusions}

This PE intervention with 3 workshops did not reduce the number of events with excessive physical workload during construction work. An exploratory analysis using higher thresholds confirmed the results. The intervention group experienced a reduced general fatigue and an increased influence on own work following the intervention, compared with the control group.

\section{Acknowledgments}

This study was supported by grants from The Danish Council for Independent Research (DFF-4092-00320). The loss of earnings for the participants was covered by The Danish Construction Association and the Danish union 3 F's "Arbejdsmiljø \& Samarbejdsfonden." The funders had no role in the study design, data collection, data analysis, the decision to publish, or preparation of the manuscript. The authors would like to thank Klaus Hansen and Sebastian Skals from The National Research Centre for the Working Environment for their great help and support during data collection. The authors would like to thank all the construction firms and the participants at the construction sites.

\section{Authors' Contributions}

MB, LLA, and PM conceived the study design. MB, LLA, and PM obtained the funding. AS, PM, MDJ, and MB were responsible for developing the technical measurement and analyzing the signals. AS developed the MatLab script. MB and LLA performed the statistical analyses. MB, LLA, JZNA, and ES designed the questionnaires. MB, LLA, and JZNA developed the program for the workshops. MB, ES, and MDJ did the data collection. MB wrote the draft of the manuscript before all authors read, critically reviewed, and approved the final version.

\section{Conflicts of Interest}

None declared. 


\section{Multimedia Appendix 1}

CONSORT - EHEALTH checklist (V 1.6.1).

[PDF File (Adobe PDF File), 342KB-Multimedia Appendix 1]

\section{Multimedia Appendix 2}

Descriptions of the workshops, including issues and solution from the participants. OHS: occupational health consultants, OHC: occupational health chief, int: internal, ext: external.

[PDF File (Adobe PDF File), 31KB-Multimedia Appendix 2]

\section{References}

1. Punnett L, Wegman DH. Work-related musculoskeletal disorders: the epidemiologic evidence and the debate. J Electromyogr Kinesiol 2004 Feb;14(1):13-23. [doi: 10.1016/j.jelekin.2003.09.015] [Medline: 14759746]

2. Brooks PM. The burden of musculoskeletal disease--a global perspective. Clin Rheumatol 2006 Nov;25(6):778-781. [doi: 10.1007/s10067-006-0240-3] [Medline: 16609823]

3. Dunning KK, Davis KG, Cook C, Kotowski SE, Hamrick C, Jewell G, et al. Costs by industry and diagnosis among musculoskeletal claims in a state workers compensation system: 1999-2004. Am J Ind Med 2010 Mar;53(3):276-284. [doi: 10.1002/ajim.20774] [Medline: 19937981]

4. Andersen LL, Fallentin N, Thorsen SV, Holtermann A. Physical workload and risk of long-term sickness absence in the general working population and among blue-collar workers: prospective cohort study with register follow-up. Occup Environ Med 2016 Apr;73(4):246-253. [doi: 10.1136/oemed-2015-103314] [Medline: 26740688]

5. Saastamoinen P, Laaksonen M, Kääriä SM, Lallukka T, Leino-Arjas P, Rahkonen O, et al. Pain and disability retirement: a prospective cohort study. Pain 2012 Mar;153(3):526-531. [doi: 10.1016/j.pain.2011.11.005] [Medline: 22340946]

6. Reeuwijk KG, Robroek SJ, Hakkaart L, Burdorf A. How work impairments and reduced work ability are associated with health care use in workers with musculoskeletal disorders, cardiovascular disorders or mental disorders. J Occup Rehabil 2014 Dec;24(4):631-639 [FREE Full text] [doi: 10.1007/s10926-013-9492-3] [Medline: 24390780]

7. Alavinia SM, de Boer AG, van Duivenbooden JC, Frings-Dresen MH, Burdorf A. Determinants of work ability and its predictive value for disability. Occup Med (Lond) 2009 Jan;59(1):32-37. [doi: 10.1093/occmed/kqn148] [Medline: 19073989]

8. Badley EM, Rasooly I, Webster GK. Relative importance of musculoskeletal disorders as a cause of chronic health problems, disability, and health care utilization: findings from the 1990 Ontario Health Survey. J Rheumatol 1994 Mar;21(3):505-514. [Medline: $\underline{8006895]}$

9. da Costa BR, Vieira ER. Risk factors for work-related musculoskeletal disorders: a systematic review of recent longitudinal studies. Am J Ind Med 2010 Mar;53(3):285-323. [doi: 10.1002/ajim.20750] [Medline: 19753591]

10. Andersen LL, Fallentin N, Ajslev JZ, Jakobsen MD, Sundstrup E. Association between occupational lifting and day-to-day change in low-back pain intensity based on company records and text messages. Scand J Work Environ Health 2017 Jan 01;43(1):68-74. [doi: 10.5271/sjweh.3592] [Medline: 27611578]

11. Sterud T, Johannessen HA, Tynes T. Work-related psychosocial and mechanical risk factors for neck/shoulder pain: a 3-year follow-up study of the general working population in Norway. Int Arch Occup Environ Health 2014 Jul;87(5):471-481. [doi: 10.1007/s00420-013-0886-5] [Medline: 23708752]

12. Sterud T. Work-related mechanical risk factors for long-term sick leave: a prospective study of the general working population in Norway. Eur J Public Health 2014 Feb;24(1):111-116. [doi: 10.1093/eurpub/ckt072] [Medline: 23748849]

13. Andersen LL, Thorsen SV, Flyvholm MA, Holtermann A. Long-term sickness absence from combined factors related to physical work demands: prospective cohort study. Eur J Public Health 2018 May 05:824-829. [doi: 10.1093/eurpub/cky073] [Medline: 29741617]

14. Mattila M, Karwowski W, Vilkki M. Analysis of working postures in hammering tasks on building construction sites using the computerized OWAS method. Appl Ergon 1993 Dec;24(6):405-412. [Medline: 15676938]

15. Hartmann B, Fleischer AG. Physical load exposure at construction sites. Scand J Work Environ Health 2005;31 Suppl 2:88-95 [FREE Full text] [Medline: 16363451]

16. Järvholm B, Stattin M, Robroek SJ, Janlert U, Karlsson B, Burdorf A. Heavy work and disability pension - a long term follow-up of Swedish construction workers. Scand J Work Environ Health 2014 Jul;40(4):335-342 [FREE Full text] [doi: 10.5271/sjweh.3413] [Medline: 24385007]

17. Rinder MM, Genaidy AM, Salem S, Shell R, Karwowski W. Interventions in the construction industry: a systematic review and critical appraisal. Hum Factors Ergon Man 2008 Mar;18(2):212-229. [doi: 10.1002/hfm.20109]

18. Gagnon D, Plamondon A, Larivière C. A biomechanical comparison between expert and novice manual materials handlers using a multi-joint EMG-assisted optimization musculoskeletal model of the lumbar spine. J Biomech 2016 Dec 06;49(13):2938-2945. [doi: 10.1016/j.jbiomech.2016.07.009] [Medline: 27469898] 
19. Jakobsen MD, Sundstrup E, Persson R, Andersen CH, Andersen LL. Is Borg's perceived exertion scale a useful indicator of muscular and cardiovascular load in blue-collar workers with lifting tasks? A cross-sectional workplace study. Eur J Appl Physiol 2014 Feb;114(2):425-434 [FREE Full text] [doi: 10.1007/s00421-013-2782-9] [Medline: 24337669]

20. Balaguier R, Madeleine P, Rose-Dulcina K, Vuillerme N. Trunk kinematics and low back pain during pruning among vineyard workers-A field study at the Chateau Larose-Trintaudon. PLoS One 2017;12(4):e0175126 [FREE Full text] [doi: 10.1371/journal.pone.0175126] [Medline: 28384277]

21. Lagersted-Olsen J, Thomsen BL, Holtermann A, Søgaard K, Jørgensen MB. Does objectively measured daily duration of forward bending predict development and aggravation of low-back pain? A prospective study. Scand J Work Environ Health 2016 Jun 01;42(6):528-537. [doi: 10.5271/sjweh.3591] [Medline: 27606607]

22. Robert-Lachaine X, Mecheri H, Larue C, Plamondon A. Validation of inertial measurement units with an optoelectronic system for whole-body motion analysis. Med Biol Eng Comput 2017 Apr;55(4):609-619. [doi: 10.1007/s11517-016-1537-2] [Medline: 27379397]

23. Wahlström J, Bergsten E, Trask C, Mathiassen SE, Jackson J, Forsman M. Full-shift trunk and upper arm postures and movements among aircraft baggage handlers. Ann Occup Hyg 2016 Oct;60(8):977-990. [doi: 10.1093/annhyg/mew043] [Medline: 27417186]

24. Samani A, Holtermann A, Søgaard K, Holtermann A, Madeleine P. Following ergonomics guidelines decreases physical and cardiovascular workload during cleaning tasks. Ergonomics 2012;55(3):295-307. [doi: 10.1080/00140139.2011.640945] [Medline: 22409167]

25. Rivilis I, Van Eerd D, Cullen K, Cole DC, Irvin E, Tyson J, et al. Effectiveness of participatory ergonomic interventions on health outcomes: a systematic review. Appl Ergon 2008 May;39(3):342-358. [doi: 10.1016/j.apergo.2007.08.006] [Medline: 17988646$]$

26. Hignett S, Wilson JR, Morris W. Finding ergonomic solutions--participatory approaches. Occup Med (Lond) 2005 May;55(3):200-207. [doi: 10.1093/occmed/kqi084] [Medline: 15857899]

27. van Eerd D, Cole D, Irvin E, Mahood Q, Keown K, Theberge N, et al. Process and implementation of participatory ergonomic interventions: a systematic review. Ergonomics 2010 Oct;53(10):1153-1166. [doi: 10.1080/00140139.2010.513452] [Medline: 20865600]

28. Driessen MT, Proper KI, van Tulder MW, Anema JR, Bongers PM, van der Beek AJ. The effectiveness of physical and organisational ergonomic interventions on low back pain and neck pain: a systematic review. Occup Environ Med 2010 Apr;67(4):277-285. [doi: 10.1136/oem.2009.047548] [Medline: 20360197]

29. Brandt M, Madeleine P, Samani A, Jakobsen MD, Skals S, Vinstrup J, et al. Accuracy of identification of low or high risk lifting during standardised lifting situations. Ergonomics 2018;61(5):710-719. [doi: 10.1080/00140139.2017.1408857] [Medline: 29171789]

30. Campbell MK, Piaggio G, Elbourne DR, Altman DG. Consort 2010 statement: extension to cluster randomised trials. Br Med J 2012;345:e5661. [Medline: 22951546]

31. Eysenbach G, CONSORT- EHEALTH Group. CONSORT-EHEALTH: improving and standardizing evaluation reports of Web-based and mobile health interventions. J Med Internet Res 2011;13(4):e126 [FREE Full text] [doi: 10.2196/jmir.1923] [Medline: 22209829]

32. Brandt M, Madeleine P, Ajslev JZ, Jakobsen MD, Samani A, Sundstrup E, et al. Participatory intervention with objectively measured physical risk factors for musculoskeletal disorders in the construction industry: study protocol for a cluster randomized controlled trial. BMC Musculoskelet Disord 2015 Oct 16;16:302 [FREE Full text] [doi: 10.1186/s12891-015-0758-0] [Medline: 26474867]

33. Ajslev J, Brandt M, Møller JL, Skals S, Vinstrup J, Jakobsen MD, et al. Reducing physical risk factors in construction work through a participatory intervention: protocol for a mixed-methods process evaluation. JMIR Res Protoc 2016 May 26;5(2):e89 [FREE Full text] [doi: 10.2196/resprot.5648] [Medline: 27230696]

34. Lewin K. Field Theory in Social Science: Selected Theoretical Papers. 1st edition. New York: Harper \& Brothers; 1964.

35. Nielsen KA, Nielsen BS. Methodologies in Action Research: Action Research and Critical Theory. Maastricht: Shaker Publishing; 2006:87.

36. Danish WEA - Arbejdstilsynet. Arbejdsrelateret muskel- og skeletbesvær: At-vejledning D.3.4 [Work-related muscle and skeletal problems] URL: https://arbejdstilsynet.dk/da/regler/at-vejledninger/a/d-3-4-arbejdsrelateret-muskel-og-skeletbesvaer [accessed 2018-10-25] [WebCite Cache ID 73Qn29Kg8]

37. Danish WEA - Arbejdstilsynet. At-vejledning D.3.1 - Løft, træk og skub [Lift, drag, and push] URL: https://arbejdstilsynet. dk/da/regler/at-vejledninger/l/d-3-1-loft-traek-og-skub [accessed 2018-10-25] [WebCite Cache ID 73QIVHtQI]

38. Brandt M, Andersen LL, Samani A, Jakobsen MD, Madeleine P. Inter-day reliability of surface electromyography recordings of the lumbar part of erector spinae longissimus and trapezius descendens during box lifting. BMC Musculoskelet Disord 2017 Dec 11;18(1):519 [FREE Full text] [doi: 10.1186/s12891-017-1872-y] [Medline: 29228936]

39. Hermens HJ, Freriks B, Disselhorst-Klug C, Rau G. Development of recommendations for SEMG sensors and sensor placement procedures. J Electromyogr Kinesiol 2000 Oct;10(5):361-374. [Medline: 11018445]

40. Seniam. URL: http://www.seniam.org/ [accessed 2018-10-28] [WebCite Cache ID 73VSjBITu] 
41. Korshøj M, Skotte JH, Christiansen CS, Mortensen P, Kristiansen J, Hanisch C, et al. Validity of the Acti4 software using ActiGraph GT3X+accelerometer for recording of arm and upper body inclination in simulated work tasks. Ergonomics 2014;57(2):247-253. [doi: 10.1080/00140139.2013.869358] [Medline: 24392673]

42. Feng Y, Wong CK, Janeja V, Kuber R, Mentis HM. Comparison of tri-axial accelerometers step-count accuracy in slow walking conditions. Gait Posture 2017 Dec;53:11-16. [doi: 10.1016/j.gaitpost.2016.12.014] [Medline: 28064084]

43. Brage S, Brage N, Ekelund U, Luan J, Franks PW, Froberg K, et al. Effect of combined movement and heart rate monitor placement on physical activity estimates during treadmill locomotion and free-living. Eur J Appl Physiol 2006 Mar;96(5):517-524. [doi: 10.1007/s00421-005-0112-6] [Medline: 16344938]

44. Kristiansen J, Korsh øj M, Skotte JH, Jespersen T, Søgaard K, Mortensen OS, et al. Comparison of two systems for long-term heart rate variability monitoring in free-living conditions--a pilot study. Biomed Eng Online 2011 Apr 12;10:27 [FREE Full text] [doi: 10.1186/1475-925X-10-27] [Medline: 21481282]

45. Madgwick SO, Harrison AJ, Vaidyanathan A. Estimation of IMU and MARG orientation using a gradient descent algorithm. IEEE Int Conf Rehabil Robot 2011;2011:5975346. [doi: 10.1109/ICORR.2011.5975346] [Medline: 22275550]

46. Jonsson B. Measurement and evaluation of local muscular strain in the shoulder during constrained work. J Hum Ergol (Tokyo) 1982 Sep;11(1):73-88. [Medline: $\underline{7186516}$ ]

47. Borg G. Borg's Perceived Exertion and Pain Scales. Champaign, IL: Human Kinetics; 1998.

48. Andersen LL, Clausen T, Persson R, Holtermann A. Dose-response relation between perceived physical exertion during healthcare work and risk of long-term sickness absence. Scand J Work Environ Health 2012 Nov;38(6):582-589 [FREE Full text] [doi: 10.5271/sjweh.3310] [Medline: 22714069]

49. Det Nationale Forskningscenter for Arbejdsmiljø. Arbejdsmiljø og helbred i Danmark. Copenhagen: Det Nationale Forskningscenter for Arbejdsmiljø; 2013.

50. Clausen T, Nielsen K, Carneiro IG, Borg V. Job demands, job resources and long-term sickness absence in the Danish eldercare services: a prospective analysis of register-based outcomes. J Adv Nurs 2012 Jan;68(1):127-136. [doi: 10.1111/j.1365-2648.2011.05724.x] [Medline: 21658095]

51. Pejtersen JH, Kristensen TS, Borg V, Bjorner JB. The second version of the Copenhagen Psychosocial Questionnaire. Scand J Public Health 2010 Feb;38(3 Suppl):8-24. [doi: 10.1177/1403494809349858] [Medline: 21172767]

52. Takala EP, Pehkonen I, Forsman M, Hansson GA, Mathiassen SE, Neumann WP, et al. Systematic evaluation of observational methods assessing biomechanical exposures at work. Scand J Work Environ Health 2010 Jan;36(1):3-24 [FREE Full text] [Medline: 19953213]

53. Eliasson K, Palm P, Nyman T, Forsman M. Inter- and intra- observer reliability of risk assessment of repetitive work without an explicit method. Appl Ergon 2017 Jul;62:1-8 [FREE Full text] [doi: 10.1016/j.apergo.2017.02.004] [Medline: 28411720]

54. van der Molen HF, Sluiter JK, Hulshof CT, Vink P, Frings-Dresen MH. Effectiveness of measures and implementation strategies in reducing physical work demands due to manual handling at work. Scand J Work Environ Health 2005;31 Suppl 2:75-87 [FREE Full text] [Medline: 16363450]

55. van der Molen HF, Grouwstra R, Kuijer PP, Sluiter JK, Frings-Dresen MH. Efficacy of adjusting working height and mechanizing of transport on physical work demands and local discomfort in construction work. Ergonomics 2004 Jun 10;47(7):772-783. [doi: 10.1080/0014013042000193309] [Medline: 15204287]

56. Luijsterburg PA, Bongers PM, de Vroome EM. A new bricklayers' method for use in the construction industry. Scand J Work Environ Health 2005 Oct;31(5):394-400 [FREE Full text] [Medline: 16273966]

57. Dale AM, Jaegers L, Welch L, Gardner BT, Buchholz B, Weaver N, et al. Evaluation of a participatory ergonomics intervention in small commercial construction firms. Am J Ind Med 2016 Jun;59(6):465-475 [FREE Full text] [doi: 10.1002/ajim.22586] [Medline: 27094450]

58. Ajslev JZ, Persson R, Andersen LL. Contradictory individualized self-blaming: a cross-sectional study of associations between expectations to managers, coworkers, one-self and risk factors for musculoskeletal disorders among construction workers. BMC Musculoskelet Disord 2017 Jan 10;18(1):13 [FREE Full text] [doi: 10.1186/s12891-016-1368-1] [Medline: 28068961]

59. Grill M, Pousette A, Nielsen K, Grytnes R, Törner M. Safety leadership at construction sites: the importance of rule-oriented and participative leadership. Scand J Work Environ Health 2017 Jul 01;43(4):375-384. [doi: 10.5271/sjweh.3650] [Medline: 28558110]

60. van der Beek AJ, Dennerlein JT, Huysmans MA, Mathiassen SE, Burdorf A, van Mechelen W, et al. A research framework for the development and implementation of interventions preventing work-related musculoskeletal disorders. Scand J Work Environ Health 2017 Nov 01;43(6):526-539. [doi: 10.5271/sjweh.3671] [Medline: 28945263]

61. Gilmore B, Vallières F, McAuliffe E, Tumwesigye NM, Muyambi G. The last one heard: the importance of an early-stage participatory evaluation for programme implementation. Implement Sci 2014 Sep 26;9:137 [FREE Full text] [doi: 10.1186/s13012-014-0137-5] [Medline: 25253191]

62. Ajslev JZ, Persson R, Andersen LL. Associations between wage system and risk factors for musculoskeletal disorders among construction workers. Pain Res Treat 2015;2015:513903 [FREE Full text] [doi: 10.1155/2015/513903] [Medline: 26605083] 
63. Ajslev JZ, Møller JL, Persson R, Andersen LL. Trading health for money: agential struggles in the (re)configuration of subjectivity, the body and pain among construction workers. Work Employ Soc 2016 Oct;31(6):887-903. [doi: $10.1177 / 0950017016668141]$

64. Kramer DM, Bigelow PL, Carlan N, Wells RP, Garritano E, Vi P, et al. Searching for needles in a haystack: identifying innovations to prevent MSDs in the construction sector. Appl Ergon 2010 Jul;41(4):577-584. [doi: 10.1016/j.apergo.2009.12.003] [Medline: 20170903]

65. Ajslev J, Lund H, Møller J, Persson R, Andersen L. Habituating pain: questioning pain and physical strain as inextricable conditions in the construction industry. Nord J Work Life Stud 2013;3(3):195-218.

66. Boatman L, Chaplan D, Teran S, Welch LS. Creating a climate for ergonomic changes in the construction industry. Am J Ind Med 2015 Aug;58(8):858-869. [doi: 10.1002/ajim.22499] [Medline: 26147396]

67. Burdorf A, van der Beek AJ. To RCT or not to RCT: evidence on effectiveness of return-to-work interventions. Scand J Work Environ Health 2016 Jul 01;42(4):257-259. [doi: 10.5271/sjweh.3577] [Medline: 27271241]

\author{
Abbreviations \\ IMU: inertial measurement units \\ MVC: maximal voluntary contraction \\ PE: participatory ergonomics \\ RMS: root mean square \\ SEMG: surface electromyography \\ WMSD: work-related musculoskeletal disorder
}

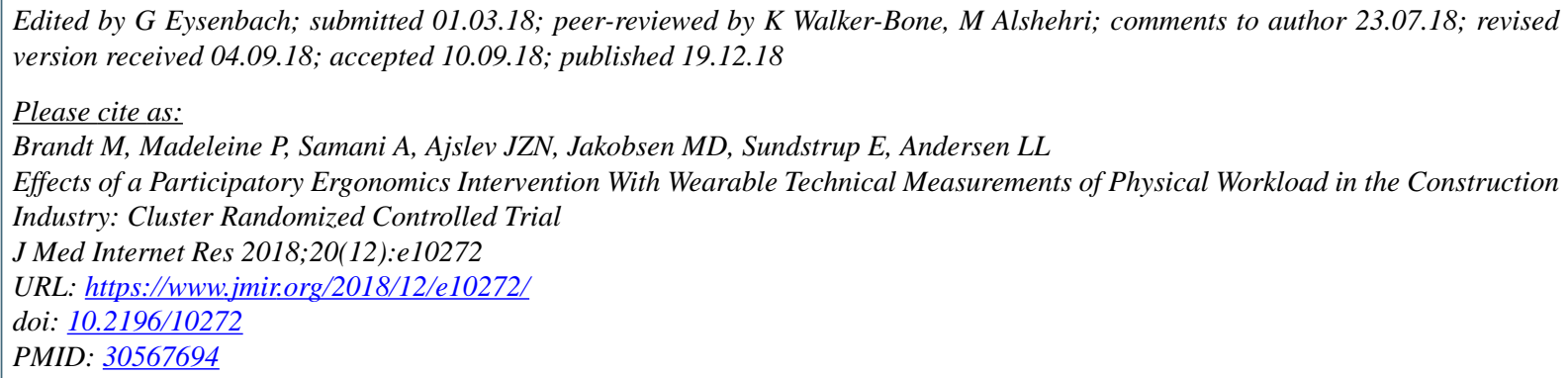

CMikkel Brandt, Pascal Madeleine, Afshin Samani, Jeppe ZN Ajslev, Markus D Jakobsen, Emil Sundstrup, Lars L Andersen. Originally published in the Journal of Medical Internet Research (http://www.jmir.org), 19.12.2018. This is an open-access article distributed under the terms of the Creative Commons Attribution License (https://creativecommons.org/licenses/by/4.0/), which permits unrestricted use, distribution, and reproduction in any medium, provided the original work, first published in the Journal of Medical Internet Research, is properly cited. The complete bibliographic information, a link to the original publication on http://www.jmir.org/, as well as this copyright and license information must be included. 